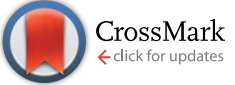

Cite this: RSC Adv., 2017, 7, 10592

Received 4th January 2017

Accepted 26th January 2017

DOI: $10.1039 / \mathrm{c} 7 \mathrm{ra00115k}$

rsc.li/rsc-advances

\section{Systematic study on preparation of copper nanoparticle embedded porous carbon by carbonization of metal-organic framework for enzymatic glucose sensor $\dagger$}

\begin{abstract}
Yoodae Song, ${ }^{a}$ Damsol Cho, ${ }^{\text {ab }}$ Sada Venkateswarlu ${ }^{a}$ and Minyoung Yoon*a
Recently, metal-organic frameworks (MOFs) have been widely used in the preparation of metal oxideembedded porous carbon composite materials. However, non-oxidized metal nanoparticle embedded porous carbon composites have rarely been prepared from MOFs to date. Herein, we present a systematic synthetic condition study of a $\mathrm{Cu}$ nanoparticle embedded porous carbon composite (CuaC-500) by simple carbonization of a copper-based MOF (HKUST-1). The conditions for the synthesis of the pure $\mathrm{Cu}$ nanoparticles embedded composite were optimized by changing the reaction temperature and time. The prepared composite retained its original octahedron shape, with uniformly distributed copper nanoparticles $(\sim 30 \mathrm{~nm})$ in the carbon bed. The composite Cu@C-500 exhibited hierarchical porosity with a moderate surface area $\left(195 \mathrm{~m}^{2} \mathrm{~g}^{-1}\right)$. Due to its hierarchical porosity and unique redox activity, CuaC-500 was examined for peroxidase-like catalytic activity, particularly for glucose sensing assays. The results indicated that this carbon composite displayed high catalytic activity similar to that of the peroxidase enzyme. Moreover, it presented one of the best detection limits $(3.2 \times$ $\left.10^{-9} \mathrm{M}\right)$ in colorimetric glucose sensing. In addition, Cu(C-500 exhibited good selectivity towards other sugars. The high sensitivity and selectivity of CuAC-500 show great potential in the development of highly efficient glucose sensing devices.
\end{abstract}

\section{Introduction}

Metal-organic frameworks (MOFs) comprise metal ions (nodes) and carbon-containing organic ligands (linkers) that are periodically connected by coordination bonds. ${ }^{1-5}$ Because of the presence of well-defined pores, MOFs show great potential in various applications, including gas storage, ${ }^{5-10}$ separation, ${ }^{\mathbf{1 1 - 1 3}}$ catalysis, ${ }^{14-18}$ transport, ${ }^{19-22}$ and sensing. ${ }^{23,24}$ However, these materials are usually unstable to moisture, and hence, their application in water-based fields has been limited. There have been several studies (the effects of coating, ${ }^{25}$ compositing, ${ }^{26}$ and carbonization on $\mathrm{MOFs}^{27-34}$ ) to overcome this problem. Notably, carbonization of MOFs is of great interest because the MOFs contains both a metal and a carbon sources for the preparation of composite materials. Therefore, simple pyrolysis of the MOF allows the formation of metal- or metal oxide-embedded carbon composite materials. In addition, pores are usually generated during the carbonization process. Therefore, porous carbon

${ }^{a}$ Department of Nanochemistry, College of Bionano, Gachon University, Sungnam, 13120, Republic of Korea. E-mail: myyoon@gachon.ac.kr

${ }^{b}$ Department of Bionanotechnology, College of Bionano, Gachon University, Sungnam, 13120, Republic of Korea

$\dagger$ Electronic supplementary information (ESI) available: XPS data and PXRD data. See DOI: $10.1039 / \mathrm{c} 7 \mathrm{ra00115k}$ composite materials can be easily prepared by a simple MOF carbonization process. As a result of this concept, the production of many metal oxide-embedded porous carbon composites has been recently reported. ${ }^{31-37}$ The prepared materials exhibited interesting catalytic activity in organic transformation, ${ }^{31}$ supercapacitor $^{33} /$ battery $^{34}$ electrode and sensing ${ }^{35-37}$ applications. However, pure metal-embedded porous carbon composites have rarely been prepared from MOFs to date. In addition, it is difficult to control the oxidation state of metal oxides in MOF during carbonization reactions. In addition, systematic synthetic condition optimization for the preparation of pure metal nanoparticle embedded system has scarcely reported. Therefore, investigation of oxidation state control, and preparation of pure metal-nanoparticle-embedded porous carbon composites from MOFs are two of the most important issues in the MOF carbonization research field.

For the preparation of pure metal-nanoparticle-embedded carbon composites, the metal in the MOF should be inert and in a neutral form. Thus, we selected copper as the metal source because of its low cost and inertness to air. We selected the best known copper-based MOF, HKUST- $1,{ }^{38}$ as the candidate. Although a similar study was reported, ${ }^{36,37}$ none of them reported pure copper nanoparticle embedded system (the reported composite was a mixture of $\mathrm{Cu}$ and $\mathrm{Cu}_{2} \mathrm{O}$ nanoparticles). 
Furthermore, none of the work has reported systematic study for the preparation of pure metal nanoparticle embedded system. For better application, however, preparation of pure copper nanoparticle embedded materials is important for further application. Herein, we present the first systematic study of pure copper nanoparticle and synthetic condition optimization of the analysis of the resulting composite materials. The systematic synthetic condition study suggests that the copper to copper oxide ratio is depending on the conditions of the carbonization reaction (temperature and time). Thus, the pure $\mathrm{Cu}$ nanoparticle embedded porous carbon composite (Cu@C-500) was prepared by carbonization of HKUST-1 at $500{ }^{\circ} \mathrm{C}$ for $10 \mathrm{~h}$. The copper nanoparticles $(30 \mathrm{~nm})$ were uniformly distributed in the carbon bed of the composite material. Porosity analysis suggested that the material has a hierarchical porosity with a modest surface area. Therefore, we predicted that the composite material should exhibit interesting catalytic activity due to the presence of redox active copper nanoparticles, and hierarchical porosity for molecular diffusion. To the best of our knowledge, this work is the first systematic study in pure metal nanoparticle embedded porous carbon synthesis by pyrolysis of MOFs.

Recently, metal nanoparticle ${ }^{39}$ or metal nanoparticle embedded composite materials have been widely used for enzyme mimicking catalysis applications. ${ }^{40}$ Among many biological catalytic reactions, peroxidase-like catalytic activity has drawn much attention due to its wide potential applications (such as decomposition of reactive oxygen species). ${ }^{41}$ The peroxidase-like catalytic activity of $\mathrm{Cu} @ \mathrm{C}-500$ has been studied using a 3,3',5,5'-tetramethylbenzidine (TMB) assay. ${ }^{40}$ In addition, Cu@C-500 was further employed in a colorimetric glucose sensing assay (Scheme 1). Interestingly, the material exhibits one of the best detection limits $\left(3.2 \times 10^{-9} \mathrm{M}\right)$ in colorimetric glucose sensing assays recorded in literature. Hierarchical porosity for enzyme and molecular diffusion and uniform

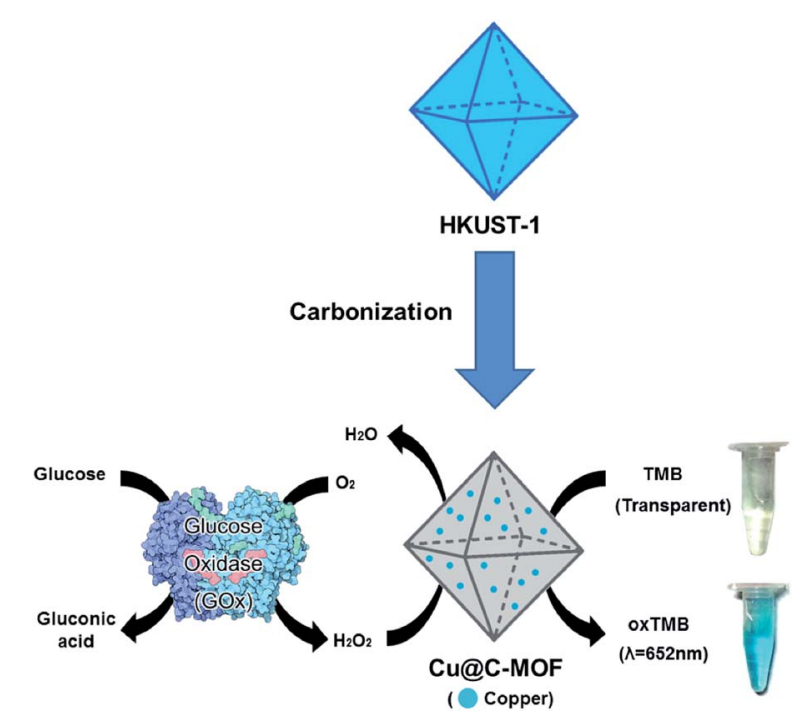

Scheme 1 Glucose sensing assay using CuaC-500 composite material. distribution of pure metal nanoparticle may affect to the high sensitivity and selectivity of the sensor material.

\section{Experimental}

\subsection{Reagents and materials}

All the sugars (glucose, mannose, galactose, sucrose, fructose), copper(II) nitrate trihydrate $\left[\mathrm{Cu}\left(\mathrm{NO}_{3}\right)_{2} \cdot 3 \mathrm{H}_{2} \mathrm{O}\right]$, glucose oxidase (GOx, >100 000 units per g), sodium acetate buffer solution, and activated carbon were purchased from Sigma-Aldrich. Benzene1,3,5-tricarboxylic acid and 3,3',5,5'-tetramethylbenzidine (TMB) were purchased from Alfa Aesar. Most of the solvents, namely, $N, N$-dimethylformamide (DMF), ethanol, glacial acetic acid, dimethyl sulfoxide (DMSO), hydrogen peroxide $\left(\mathrm{H}_{2} \mathrm{O}_{2}\right.$, $34.5 \%$ ), and phosphate buffered-saline (PBS) buffer were purchased from a Korean chemical company (Samchun chemical). All the chemicals were used as received without further purification. Deionized Millipore water was used to prepare all the solutions.

\subsection{Preparation of HKUST-1}

Benzene-1,3,5-tricarboxylic acid $(0.25 \mathrm{~g}, 1.2 \mathrm{mmol})$ and copper(II) nitrate trihydrate $(0.52 \mathrm{~g}, 2.15 \mathrm{mmol})$ were stirred for $15 \mathrm{~min}$ in $12 \mathrm{~mL}$ of a solvent that is a $1: 1: 1$ mixture of DMF, ethanol, and deionized water. ${ }^{38}$ The resultant solution was divided into two portions ( $6 \mathrm{~mL}$ each) in $20 \mathrm{~mL}$ vials. The vials were tightly sealed and placed in an oven at $80{ }^{\circ} \mathrm{C}$ for $20 \mathrm{~h}$. Blue octahedral crystals were afforded ( $85 \%$ yield). The crystals were washed with DMF $(10 \mathrm{~mL} \times 3$ times $)$, and stored under DMF until use. The solid was dried at $100{ }^{\circ} \mathrm{C}$ under dynamic vacuum before use to avoid the effect of the solvent during carbonization.

\subsection{Synthesis of Cu@C-400, 500, 700}

Copper-nanoparticle-embedded porous carbon composites were prepared by the simple pyrolysis of a copper-containing MOF (HKUST-1) at various temperatures under a $\mathrm{N}_{2}$ flow. For the preparation of the $\mathrm{Cu}$ (C) composites, dried HKUST-1 was placed in an alumina boat at the center of a tube furnace. An inert atmosphere $\left(\mathrm{N}_{2}\right)$ was achieved by applying five cycles of $\mathrm{N}_{2}$ and vacuum purges. The temperature of the tube furnace was elevated to the target temperature $\left(400,500\right.$, and $\left.700{ }^{\circ} \mathrm{C}\right)$ with a heating rate of $10{ }^{\circ} \mathrm{C} \mathrm{min}{ }^{-1}$ under $\mathrm{N}_{2}$ flow $\left(150 \mathrm{~cm}^{3} \mathrm{~min}^{-1}\right)$. Various reaction times $(6,8$, and $10 \mathrm{~h})$ were used to establish the optimal temperature. The sample was cooled down naturally to room temperature, under $\mathrm{N}_{2}$ flow, and the product was recovered from the alumina boat ( $35 \%$ yield).

\subsection{Characterization}

The prepared $\mathrm{Cu} @ \mathrm{C}$ composites were analyzed using a Rigaku Ultima III X-ray diffractometer equipped with a $\mathrm{Cu}$ sealed tube $(\lambda=1.54178 \AA$ ). The following conditions were used: $40 \mathrm{kV}, 30$ $\mathrm{mA}$, increment $=0.05^{\circ}$, scan speed $=3 \mathrm{deg} \mathrm{min}^{-1}$. The size and morphology of the $\mathrm{Cu} @ \mathrm{C}$ composites were determined by a scanning electron microscope (SEM) with an accelerating voltage of $30 \mathrm{kV}$ (JEOL-7500F), and a transmission electron 
microscope (TEM) with an accelerating voltage of $300 \mathrm{kV}$ (Tecnai G2). Detailed structural and compositional studies were carried out using a PHI-Quantera II X-ray photoelectron spectrometer (XPS) with a monochromatic $\mathrm{Al} \mathrm{K} \alpha$ line X-ray setting $(200 \mu \mathrm{m}, 50 \mathrm{~W}, 15 \mathrm{kV})$. The specific surface areas and pore diameters of the products were calculated from a $\mathrm{N}_{2}$ adsorption isotherm measured by Micromeritics ASAP-2020; high-purity nitrogen gas (99.999\%) was used for the measurements. Data from C, H, N, S elemental analysis was obtained using a VarioMICRO cube. Electronic absorption spectra were measured on a Shimadzu UV-Vis spectrophotometer (UV-2550) with a wavelength range of $300-800 \mathrm{~nm}$.

\subsection{Colorimetric $\mathrm{H}_{2} \mathrm{O}_{2}$ sensing activity study}

Prior to the study of glucose sensing activity, the $\mathrm{H}_{2} \mathrm{O}_{2}$ sensing activity of the composites was examined by TMB assay. ${ }^{40}$ The TMB stock solution was prepared by dissolving TMB $(0.250 \mathrm{~g}$, $1.04 \mathrm{mmol})$ in $\mathrm{H}_{2} \mathrm{O}(9.800 \mathrm{~mL})$ and DMSO $(0.200 \mathrm{~mL})$. The catalyst (HKUST-1, Cu@C, copper foil, or activated carbon) stock solution was prepared by dispersing the catalyst $(4 \mathrm{mg})$ in $10 \mathrm{~mL}$ of sodium acetate buffer solution. The TMB-based $\mathrm{H}_{2} \mathrm{O}_{2}$ sensing experiment was carried out by mixing the catalyst stock solution $(50 \mu \mathrm{L})$, TMB stock solution $(100 \mu \mathrm{L})$, and $\mathrm{H}_{2} \mathrm{O}_{2}(100 \mu \mathrm{L})$ in sodium acetate buffer solution $(1000 \mu \mathrm{L})$. The resultant solution was incubated in a shaker for $3 \mathrm{~min}$ at room temperature. This was followed by filtration of the solid catalyst using a disk filter (PTFE, $0.5 \mu \mathrm{m}$ ). To monitor the $\mathrm{H}_{2} \mathrm{O}_{2}$ sensing activity, the absorbance of the filtered solution was measured by UV-Vis spectroscopy.

\subsection{GOx-based colorimetric sensing study}

For the study of glucose sensing activity using GOx enzymes, ${ }^{40}$ a GOx solution $\left(1 \mu \mathrm{g} \mu \mathrm{L}^{-1}\right)$ was prepared from a PBS buffer solvent. The sugar (glucose, mannose, galactose, sucrose, or fructose) stock solution $(500 \mu \mathrm{M})$ was prepared by dissolution of the sugar in a PBS buffer solution. This was diluted to the designated concentration before use. The $\mathrm{Cu@C} \mathrm{solution} \mathrm{was}$ prepared by dispersing the catalyst $(4 \mathrm{mg})$ in $10 \mathrm{~mL}$ sodium acetate buffer solution ( $\mathrm{pH} 4.5)$. The TMB solution was prepared by dissolving TMB $(0.250 \mathrm{~g}, 1.04 \mathrm{mmol})$ in $\mathrm{H}_{2} \mathrm{O}(9.800 \mathrm{~mL})$ and DMSO $(0.200 \mathrm{~mL})$. The GOx enzyme-based glucose sensing experiment was carried out by mixing the GOx $(10 \mu \mathrm{L})$ and sugar $(300 \mu \mathrm{L})$ solutions. The mixture was incubated in an isothermal shaker at $40^{\circ} \mathrm{C}$ for $3 \mathrm{~min}$. The $\mathrm{Cu} @ \mathrm{C}(50 \mu \mathrm{L})$ and TMB $(100 \mu \mathrm{L})$ solutions were then added to the enzyme solution. This was followed by incubation in an isothermal shaker at $40{ }^{\circ} \mathrm{C}$ for $3 \mathrm{~min}$. The reaction mixture was filtered using a disk filter (PTFE, $0.5 \mu \mathrm{m}$ ), and the absorbance of the resultant solution was measured by UV-Vis spectroscopy.

\section{Results and discussion}

\subsection{Synthesis of the $\mathrm{Cu} @ \mathrm{C}$ composites}

Although a couple of research groups have used HKUST-1 for the preparation of copper oxide-embedded porous carbon composite materials, ${ }^{36,37}$ the formation of a pure copper-

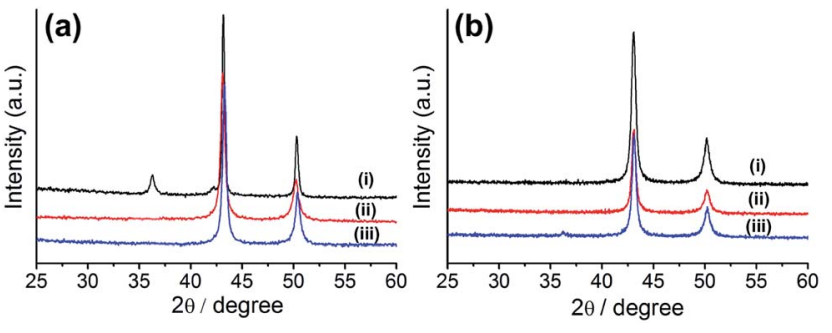

Fig. 1 (a) PXRD profiles of $\mathrm{Cu}$ embedded porous carbon prepared at temperatures of: (i) $700{ }^{\circ} \mathrm{C}$, (ii) $500{ }^{\circ} \mathrm{C}$, and (iii) $400{ }^{\circ} \mathrm{C}$ for $10 \mathrm{~h}$; (b) PXRD profiles of $\mathrm{Cu}$ embedded carbon prepared at reaction times of (i) $10 \mathrm{~h}$, (ii) $8 \mathrm{~h}$, and (iii) $6 \mathrm{~h}$ at $500^{\circ} \mathrm{C}$.

nanoparticle-embedded porous carbon composite is unprecedented. Therefore, we tried to optimize the synthetic conditions for the preparation of this composite by varying the reaction conditions (time and temperature). For the preparation of metal-embedded porous carbon composites, we applied the pyrolysis method using a tube furnace under $\mathrm{N}_{2}$ flow, as reported in literature. Hence, HKUST-1 was carbonized at various temperatures $\left(400,500\right.$, and $\left.700{ }^{\circ} \mathrm{C}\right)$ for $10 \mathrm{~h}$. The composites prepared at various temperatures were characterized by powder X-ray diffraction (PXRD, Fig. 1a). The composite prepared at $700{ }^{\circ} \mathrm{C}(\mathrm{Cu} @ \mathrm{C}-700)$ displayed both copper oxide $\left(\mathrm{Cu}_{2} \mathrm{O}: 36.5^{\circ}\right.$ and $42.1^{\circ}$, JCPDS 05-0667) and copper (Cu: $43.6^{\circ}$ and $50.8^{\circ}$, JCPDS 04-0836) nanoparticle PXRD peaks, suggesting the formation of a $\mathrm{Cu} / \mathrm{Cu}_{2} \mathrm{O}$ mixture. However, the composites prepared at $400(\mathrm{Cu} @ \mathrm{C}-400)$ and $500{ }^{\circ} \mathrm{C}(\mathrm{Cu} @ \mathrm{C}-500)$ displayed PXRD peaks at $43.6^{\circ}$ and $50.8^{\circ}$ corresponding to (111) and (200) planes of pure copper nanoparticles, respectively. The particle size for $\mathrm{Cu} @ \mathrm{C}-500$ was $28 \mathrm{~nm}$. This was determined by applying the Scherrer equation $[D=0.89 \lambda / \beta \cos \theta$, where $D$ is the average particle size, $\lambda$ is the wavelength of the $\mathrm{Cu}-\mathrm{K} \alpha$ irradiation, $\beta$ is the intensity at the full width of half the maximum peak height of the diffraction peak, and $\theta$ is the diffraction angle for the (111) peak].

The temperature experiments indicated that the carbon bed in the composites can work as a reducing agent during their synthetic process. Simultaneously, high reaction temperatures $\left(>600{ }^{\circ} \mathrm{C}\right)$ allow the formation of a partially oxidized $\mathrm{Cu}_{2} \mathrm{O}$ species, resulting in the formation of a $\mathrm{Cu} / \mathrm{Cu}_{2} \mathrm{O}$ composite material. For optimization of the pyrolysis time, we fixed the reaction temperature at $500{ }^{\circ} \mathrm{C}$. This value was chosen because we supposed that a temperature of $400{ }^{\circ} \mathrm{C}$ would not be high enough for successful carbon bed formation to occur. The MOF was carbonized for various reaction times $(6,8$, and $10 \mathrm{~h})$, and the products were characterized by PXRD analysis (Fig. 1b). The results suggest that $\mathrm{Cu}_{2} \mathrm{O}$ peaks (at $36.5^{\circ}$ and $42.1^{\circ}$ ) begin to appear as decreasing the pyrolysis time. This gives an indication of the minimum time required for the complete reduction of the copper ions. Therefore, we concluded that the pure copperembedded porous carbon composite was successfully prepared by pyrolysis of HKUST- 1 at $500{ }^{\circ} \mathrm{C}$ for $10 \mathrm{~h}$, under $\mathrm{N}_{2}$ flow. Hence, we propose that the optimum temperature and reaction time for the preparation of pure $\mathrm{Cu}$ nanoparticle embedded porous carbon composites are $500{ }^{\circ} \mathrm{C}$ and $10 \mathrm{~h}$, respectively. 


\subsection{Characterization of the $\mathrm{Cu}$ embedded carbon composites}

To understand the chemical and physical properties of the materials formed, we characterized the composite materials using various analytical methods. The PXRD results suggest the presence of $\mathrm{Cu}$ and/or $\mathrm{Cu}_{2} \mathrm{O}$ nanoparticles, depending on the reaction temperatures. X-ray photoelectron spectroscopy (XPS) was carried out in order to understand the composition and valence states of $\mathrm{C}, \mathrm{O}$, and $\mathrm{Cu}$ in the $\mathrm{Cu}$ embedded carbon composites. Fig. 2 illustrates the survey scan and $\mathrm{Cu} 2 \mathrm{p}$ core level binding energy spectra of the $\mathrm{Cu}$ embedded carbon composites synthesized at various temperatures $(400,500$, and $700{ }^{\circ} \mathrm{C}$ ). The indexed four peaks in the survey spectrum at $284 \mathrm{eV}, 399.7 \mathrm{eV}, 530 \mathrm{eV}$, and $932 \mathrm{eV}$ corresponding to C 1s, N 1s, $\mathrm{O} 1 \mathrm{~s}$ and $\mathrm{Cu} 2 \mathrm{p}$, respectively, indicates the presence of $\mathrm{C}, \mathrm{N}, \mathrm{O}$, and $\mathrm{Cu}$ in the composite (Fig. 2). The core level binding energy spectrum of Cu 2p (Fig. 2b) offered a more detailed explanation. For Cu@C-700, the peaks at $932.09 \mathrm{eV}\left(2 \mathrm{p}_{3 / 2}\right)$ and $952.1 \mathrm{eV}$ $\left(2 \mathrm{p}_{1 / 2}\right)$ for $\mathrm{Cu}(0)$, and those at $934.1 \mathrm{eV}\left(2 \mathrm{p}_{1 / 2}\right)$ and $954.39 \mathrm{eV}$ $\left(2 \mathrm{p}_{1 / 2}\right)$ for $\mathrm{Cu}^{2+}$ [Fig. $2 \mathrm{~b}$ line (i)] indicate the presence of a metallic copper and copper oxide $(\mathrm{Cu}(40.9 \%) / \mathrm{CuO}(59.1 \%))$. In addition, line (i) displays shake-up peaks (S1 and S2) that correspond to $\mathrm{CuO}$, and are related to the $\mathrm{d}^{9}$ configuration in the ground state of $\mathrm{Cu}^{2+} \cdot{ }^{22}$ On the other hand, $\mathrm{Cu@C-400}$ [Fig. 2b line (iii)] and Cu@C-500 [Fig. 2b line (ii)] exhibit $\mathrm{Cu}$ 2p XPS peaks that are in a similar position to those of $\mathrm{Cu}$ @C700 , without the presence of shake-up peaks. This suggests the presence of non-oxidized copper. These results clearly prove that $\mathrm{Cu@C-700} \mathrm{comprises} \mathrm{a} \mathrm{mixture} \mathrm{of} \mathrm{copper} \mathrm{and} \mathrm{copper} \mathrm{oxide}$ nanoparticles, whereas Cu@C-500 and Cu@C-400 are made up of pure copper nanoparticles.
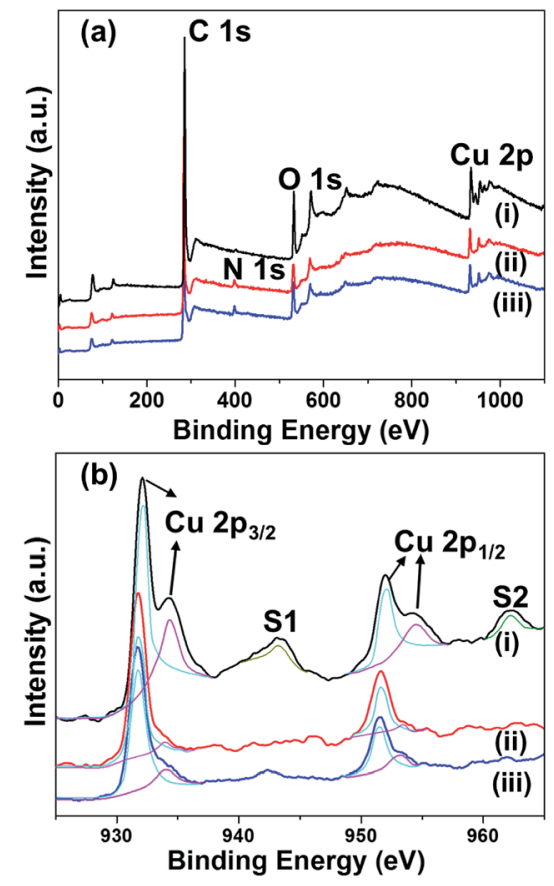

Fig. 2 (a) Wide scan XPS spectra, and (b) high resolution XPS spectra of Cu 2p for: (i) CuaC-700, (ii) CuaC-500, and (iii) CuaC-400.
Table 1 Elemental analysis data of the composites

\begin{tabular}{llll}
\hline & $\mathrm{N}(\%)$ & $\mathrm{C}(\%)$ & $\mathrm{H}(\%)$ \\
\hline $\mathrm{Cu} @ \mathrm{C}-700$ & 0.23 & 14.94 & 0.27 \\
$\mathrm{Cu@C-500}$ & 0.93 & 26.70 & 0.90 \\
Cu@C-400 & 1.14 & 26.14 & 1.12 \\
\hline
\end{tabular}

High resolution XPS spectra for carbon and oxygen were also investigated. The carbon XPS spectra indicate that $\mathrm{Cu@C-700}$ exhibits a peak shift from 289.1 to $290.7 \mathrm{eV}$. This is attributed to the decomposition of the $\mathrm{C}=\mathrm{O}$ groups, followed by the formation of intact aromatic carbons $\left(\pi-\pi^{*}\right.$; Fig. S1a $\left.\dagger\right)$. Conversely, carbon XPS data of Cu@C-500 and Cu@C-400 have similar XPS peaks at $284.08 \mathrm{eV}$ and $289.1 \mathrm{eV}$ that are ascribed to the $\mathrm{sp}^{2}$ carbon of the $\mathrm{C}=\mathrm{C}$ and $\mathrm{O}-\mathrm{C}=\mathrm{O}$ moieties, respectively (Fig. S1b and $c^{\dagger}$ ). These results confirm the completion of carbonization at $700{ }^{\circ} \mathrm{C}$. The oxygen XPS spectra for $\mathrm{Cu@C-400}$ and Cu@C-500 [Fig. S1f and e†] display peaks at 530.9 and $533.1 \mathrm{eV}$ attributed to $\mathrm{C}=\mathrm{O}$ and $\mathrm{O}-\mathrm{C}=\mathrm{O}$ groups, respectively. On the other hand, the carbonyl peaks disappeared for the Cu@C-700 composite, and a new low binding energy peak [Fig. S1d†] at $529.8 \mathrm{eV}$, correspond to $\mathrm{Cu}^{2+}$ ion, which indicates presence of $\mathrm{CuO}$ at $700{ }^{\circ} \mathrm{C}$ and the results are well coincide with the literature. ${ }^{43}$ Moreover, we observed high binding energy peaks in the region of 531.3-532.8 eV. Such peaks are usually attributed to chemisorbed and dissociated oxygen species $\left(\mathrm{O}_{2}{ }^{-}\right.$, $\mathrm{O}_{2}{ }^{2-}$, or $\left.\mathrm{O}^{-}\right){ }^{44}$ The XPS data clearly confirm the formation of $\mathrm{CuO}$ at $700{ }^{\circ} \mathrm{C}$.

In addition to the above mentioned qualitative analysis, the quantitative content of carbon, hydrogen, and nitrogen in the composites was analyzed by elemental analysis (Table 1). Both

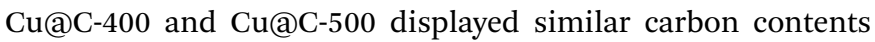
but the hydrogen and nitrogen content for $\mathrm{Cu@C-500} \mathrm{was} \mathrm{lower}$ than those of $\mathrm{Cu}$ (C-400. This suggests that the degree of carbonization increases at higher temperatures. In addition, Cu@C-700 displayed negligible amounts of hydrogen and nitrogen, and a carbon content of 15\%, suggesting a high degree of carbonization. Moreover, large amounts of carbon might be removed in $\mathrm{CO}_{2}$ form at high temperatures $\left(700{ }^{\circ} \mathrm{C}\right)$ resulting in a low carbon content.

The porosity of the material is also an important factor for applications because of the accessibility of the reactant to the catalytic sites. Because porosity is only found in the carbon bed of the material, the surface area is expected to be proportional to the carbon content of the composite. The porosity of the materials was analyzed by $\mathrm{N}_{2}$ adsorption experiments at $77 \mathrm{~K}$ (Fig. 3a). Although the surface area of the composite materials drastically decreased when compared to the starting material (HKUST-1), the composite materials exhibited interesting hierarchical porosity. Thus, $\mathrm{Cu@C-700} \mathrm{displayed} \mathrm{a} \mathrm{small} \mathrm{surface}$ area $\left(114 \mathrm{~m}^{2} \mathrm{~g}^{-1}\right)$, while a slightly smaller surface area was noted in Cu@C-400. This occurred because the temperature at which the latter material is formed $\left(400{ }^{\circ} \mathrm{C}\right)$ may not be high enough for micropore evolution to occur. In addition, at very high temperatures $\left(\geq 700{ }^{\circ} \mathrm{C}\right)$ the carbon bed starts to 

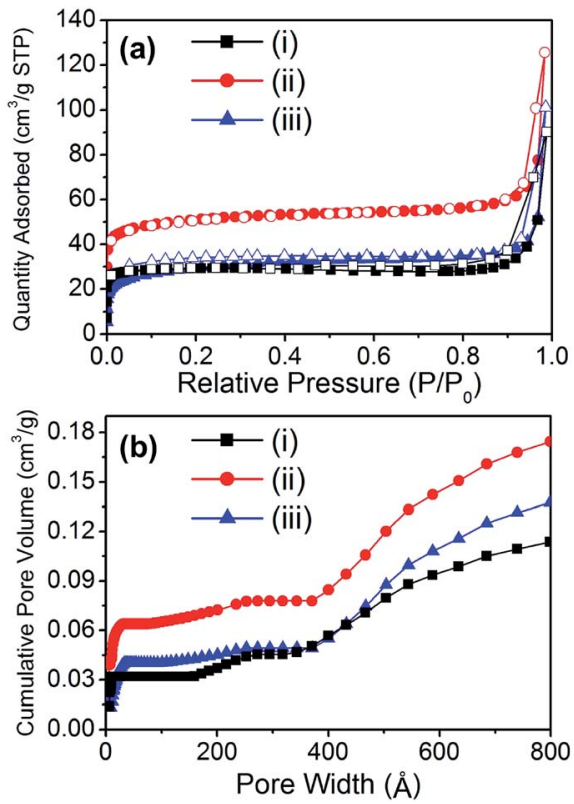

Fig. 3 (a) $\mathrm{N}_{2}$ adsorption-desorption isotherms at $77 \mathrm{~K}$ (filled symbol: adsorption, open symbol: desorption), and (b) cumulative pore volume of (i) Cuac-700, (ii) CuaC-500, and (iii) Cu@C-400.

Table 2 Surface area and pore volume of the composites

\begin{tabular}{lll}
\hline & BET S. A. $\left(\mathrm{m}^{2} \mathrm{~g}^{-1}\right)$ & Total pore volume $\left(\mathrm{cm}^{3} \mathrm{~g}^{-1}\right)$ \\
\hline Cu@C-700 & 114 & 0.129 \\
Cu@C-500 & 195 & $\mathbf{0 . 1 7 4}$ \\
Cu@C-400 & 106 & 0.145
\end{tabular}

decompose, resulting in a decrease in surface area. On the other hand, the composite prepared at $500{ }^{\circ} \mathrm{C}$ had a surface area $(195$ $\mathrm{m}^{2} \mathrm{~g}^{-1}$ ) that was twice as large as that of the other composites. This may be due to two reasons: a temperature high enough for pore evolution to occur, and a large carbon content.

In composite materials, diffusivity is an important physical property that gives a better understanding of their catalytic activity. Thus, the cumulative pore volume of the composites was calculated by analyzing their $\mathrm{N}_{2}$ adsorption isotherms (Fig. 3b). Despite having a small mesopore $(2 \mathrm{~nm}<$ pore size $<$ $50 \mathrm{~nm}$ ) volume portion, all the composites displayed hierarchical porosity comprising micro-, meso-, and macropores (Table 2). The composite $\mathrm{Cu} @ \mathrm{C}-500$ had the largest surface area, and hence the largest total pore volume $\left(0.174 \mathrm{~cm}^{3} \mathrm{~g}^{-1}\right)$. The hierarchical porosity of the composite materials aids the diffusion of enzymes and reactants. This affords better accessibility of the catalytic sites. As a result, a better enzymatic catalytic activity of the composite materials is expected. In addition, porosity analysis of the composites suggested that Cu@C-500 exhibits the best catalytic activity due to its higher porosity.

The external morphology and inner distributions of the nanoparticles were analyzed by SEM and TEM. Since we had
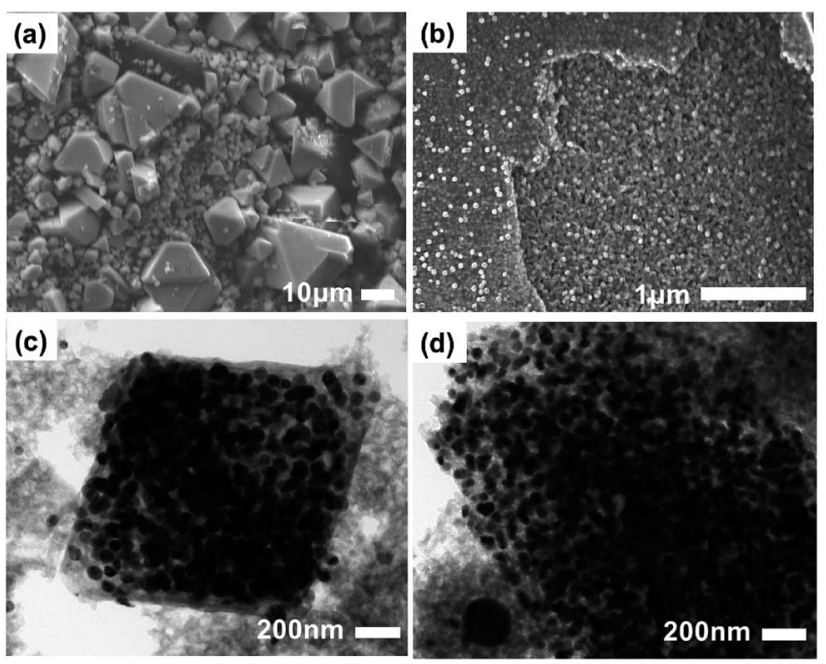

Fig. 4 ( $a$ and b) SEM and ( $c$ and d) TEM images of CuaC -500.

previously established that the optimal temperature for further applications was $500{ }^{\circ} \mathrm{C}$, we opted to use Cu@C-500 (largest surface area and carbon content) for this analysis. The SEM images clearly illustrate that despite the irregular crystal size, the octahedral shape of HKUST-1 was retained even after carbonization (Fig. S4 $\uparrow$ and 4a).

The high resolution SEM image indicates that the composite comprises very small nanoparticles (Fig. 4b). Notably, macropores are also visible in this image. Furthermore, TEM images revealed the presence of copper nanoparticles that were $30 \mathrm{~nm}$ in size, and uniformly distributed in the composite material. It should be noted that the nanoparticle size calculated from the PXRD data is well matched with that calculated from the TEM images. In addition, the carbon bed surrounding the copper nanoparticles, is visible as a transparent grey surrounding (Fig. 4c and d). The images clearly demonstrate that the copper nanoparticles have a uniform nanoparticle size, and are well distributed in the composite. Therefore, based on these results, we concluded that the pyrolysis of HKUST- 1 at $500{ }^{\circ} \mathrm{C}$ affords a well dispersed copper-nanoparticle-embedded porous carbon composite material with an average copper nanoparticle size of $30 \mathrm{~nm}$, and hierarchical porosity derived from the carbon bed. The prepared composite can be utilized in various applications including the catalytic conversion of biomolecules.

\subsection{TMB-based sensing test}

The peroxidase-like activity of these composite materials was tested by the oxidation of TMB in the presence of $\mathrm{H}_{2} \mathrm{O}_{2}$. TMB is colorless and displays no absorbance, even in the presence of $\mathrm{H}_{2} \mathrm{O}_{2}$. However, upon the addition of copper nanoparticle composite materials, the TMB solution exhibited a color change (colorless to deep blue), and two maximum absorption peaks at 370 and $652 \mathrm{~nm}$. These properties were utilized to examine the peroxidase-like activity of our composite materials, and other

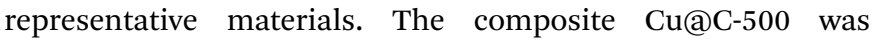
employed for the peroxidase-like activity assay, while pristine HKUST-1, activated carbon, and grinded copper foil were used 


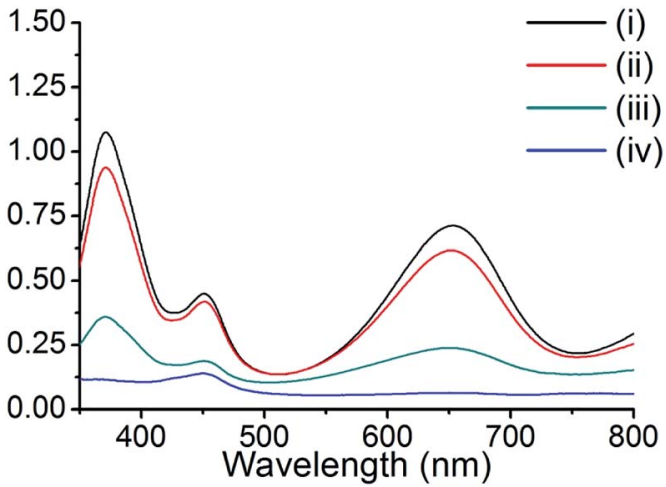

Fig. 5 UV-Vis absorption of TMB in the peroxidase-like activity study for (i) Cu@C-500, (ii) HKUST-1, (iii) copper foil, and (iv) activated carbon.

as controls. The degree of reaction was monitored by UV-Vis absorption spectroscopy (Fig. 5). The resultant spectra indicated the absence of UV-Vis absorption for the activated carbon sample [Fig. 5, line (iv)], whereas, minor UV-Vis absorptions at 370 and $652 \mathrm{~nm}$ were observed for the copper foil sample. Therefore, we concluded that copper metal can act as a catalytic site for the peroxidase-like activity assay. We also predicted that Cu@C-500 would show significant catalytic activity. This was clearly confirmed by the increase in absorption at 370 and $652 \mathrm{~nm}$. In addition, HKUST-1 also exhibited peroxidase-like catalytic activity in the TMB- $\mathrm{H}_{2} \mathrm{O}_{2}$ assay. Copper ions in HKUST-1 play an important role in the assay, and therefore, we predicted that HKUST-1 would lose its crystallinity and catalytic activity after the first assay. The PXRD experiment clearly indicated that the crystallinity of HKUST-1 totally disappeared after the first catalytic activity assay (Fig. S2 $\dagger$ ). Therefore, catalytic activity scarcely appeared after the first sensing assay.

\subsection{Glucose sensing assay using $\mathrm{Cu} @ \mathrm{C}$ composites}

For the glucose sensing assay by assistance of enzyme (glucose oxidase), there are several requirements; (1) pure metal nanoparticle in porous carbon without any metal oxide (the presence of metal oxide reduce the catalytic activity) and (2) hierarchical porosity for the diffusion of large enzyme and small analytes (glucose). It is expected that the prepared Cu@C-500 is one of the ideal platform for an application as an enzymatic glucose sensor. The GOx enzyme is an oxidoreductase enzyme that catalyzes the transformation of glucose to D-glucose-1,5-lactone and $\mathrm{H}_{2} \mathrm{O}_{2}$ in the presence of $\mathrm{O}_{2}$. The $\mathrm{H}_{2} \mathrm{O}_{2}$ afforded from the GOx reaction can be used for the quantitative analysis of glucose by a TMB-based peroxidase-like activity assay. Therefore, the prepared materials can be applied to this assay. The GOx-TMB glucose sensing assay can be carried out via two processes: (1) $\mathrm{H}_{2} \mathrm{O}_{2}$ generation by the reaction of GOx and glucose and (2) quantitative $\mathrm{H}_{2} \mathrm{O}_{2}$ assay by a peroxidase-like activity test using copper nanoparticle composite materials. Three composites (Cu@C-700, Cu@C-500, and $\mathrm{Cu@C-400)} \mathrm{were} \mathrm{used} \mathrm{to} \mathrm{deter-}$ mine the best material suitable for application to the quantitative glucose sensing assay. Glucose solutions with different

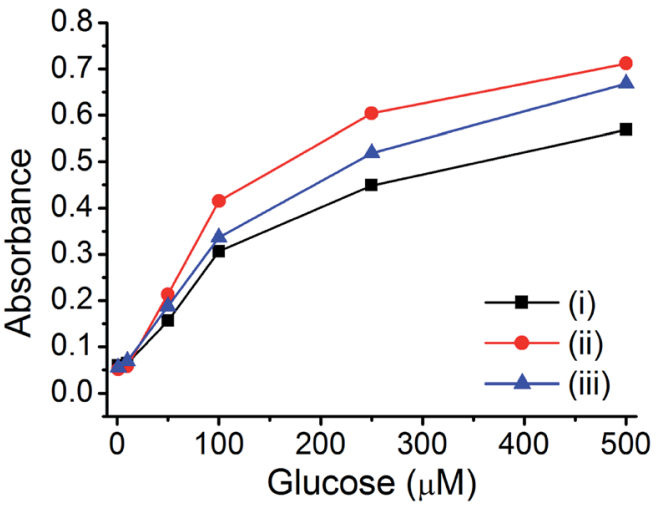

Fig. 6 GOx-based glucose sensing assay using (i) CuaC-700, (ii) Cu@C-500, and (iii) CuaC-400.

glucose concentrations $(500,300,100,50,10$, and $1 \mu \mathrm{M})$ were used for the assay, and the results are summarized in Fig. 6. As expected, Cu@C-500 [Fig. 6, line (ii)] exhibits the highest absorbance, indicating the best catalytic activity for glucose sensing. A higher catalytic activity would be useful for better sensitivity and a higher detection limit of the sensing assay. Interestingly, Cu@C-700 displayed the weakest absorption signal [Fig. 6, line (i)], indicating the least catalytic activity. This was attributed to the mixed $\mathrm{Cu}$ and $\mathrm{Cu}_{2} \mathrm{O}$ nanoparticles that may decrease the catalytic activity of $\mathrm{Cu@C-700} \mathrm{in} \mathrm{the} \mathrm{glucose}$ sensing assay.

\subsection{Quantitative glucose sensing assay using $\mathrm{Cu} @ \mathrm{C}-500$}

The copper nanoparticle composite can also be used for the quantitative assay of glucose. This is useful for biological applications. For this assay, we employed $\mathrm{Cu@C-500} \mathrm{since} \mathrm{it}$ displayed the best catalytic activity. To plot the calibration curve, we measured the UV-Vis spectra of the glucose sensing assay solution at concentrations ranging between $50-350 \mu \mathrm{M}$, at $50 \mu \mathrm{M}$ intervals (Fig. 7a). The UV-Vis absorbance of the assay solutions decreased with a decrease in glucose concentration. The colors of the assay solutions are illustrated in Fig. 7b. A decrease in color intensity (from light blue to transparent), attributed to a decrease in glucose concentration, was observed as the glucose concentration decreased from $350 \mu \mathrm{M}$ to $<50 \mu \mathrm{M}$.

A calibration curve was plotted to confirm these results (Fig. 8). The absorption band at $652 \mathrm{~nm}$ was selected, and the absorbance of the assay solution was linearly fitted to the glucose concentration with an $R^{2}$ value of 0.994 . The detection limit calculated from the calibration curve was at a glucose concentration of $320 \mathrm{nM}\left(3.2 \times 10^{-9} \mathrm{M}\right)$. This is one of the best values for colorimetric glucose sensing materials, reported in literature. ${ }^{45-47}$ We concluded that the hierarchical porosity and uniformly distributed $\mathrm{Cu}$ nanoparticles in the carbon bed afford the best glucose detection limit in the colorimetric glucose sensing assay.

\subsection{Glucose sensing selectivity and recyclability}

Analytes in real biological samples contain various sugars. Therefore, the selected composite material should demonstrate 

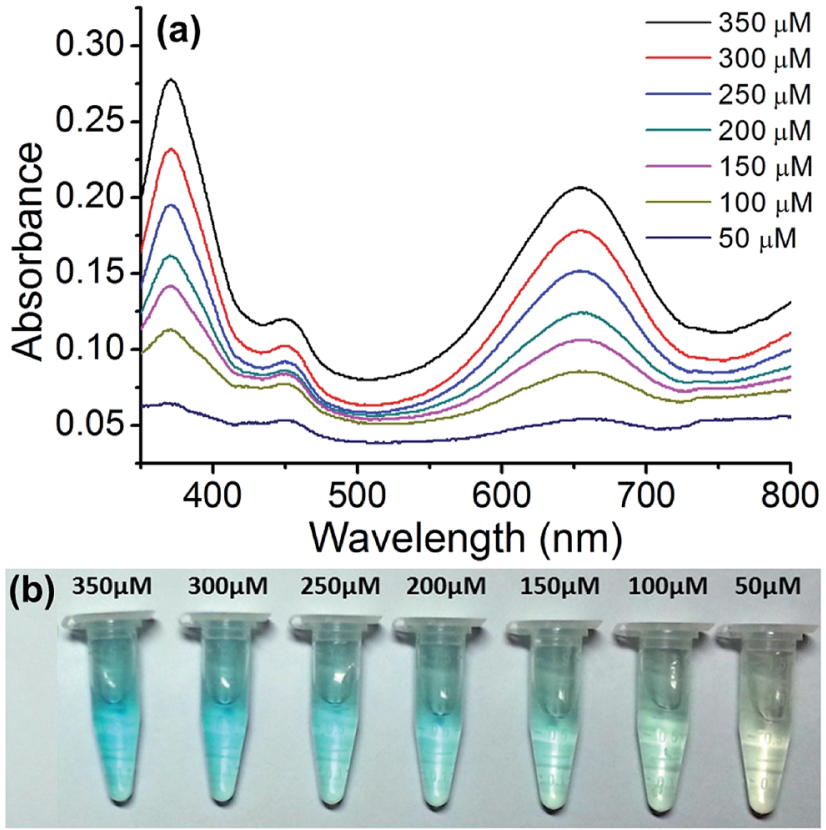

Fig.7 Quantitative glucose sensing assay using Cu(C-500. (a) UV-Vis spectra of the assay solution, and (b) images of the sensing solutions in e-tubes.

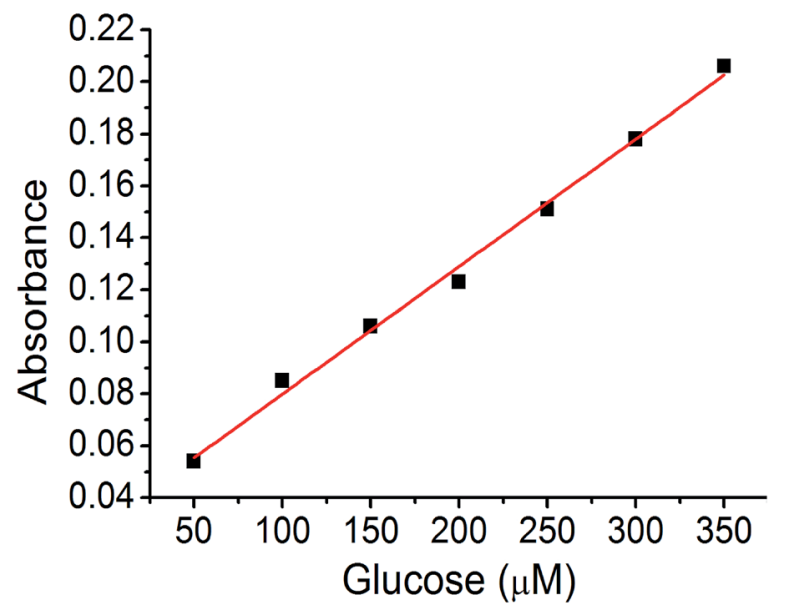

Fig. 8 Linear fit of the glucose sensing assay using CuaC-500.

high selectivity towards other sugars without disturbing the catalytic reaction. Thus, four more sugars (mannose, galactose, fructose, and sucrose) were selected for the study of glucose selectivity (Fig. 9). Sugar solutions $(300 \mu \mathrm{M})$ were prepared and used for the GOx-TMB assay. Color changes were observed in the glucose solution, with a high absorbance at $652 \mathrm{~nm}$ in the UV-Vis spectrum. Conversely, no visible color change was observed in the other sugar solutions, and there was negligible absorbance at $652 \mathrm{~nm}$. This was attributed to the absence of $\mathrm{H}_{2} \mathrm{O}_{2}$ generation in the reaction of these sugars with GOx. Therefore, we concluded that these sugars will not disturb the sensing of glucose in a GOx-TMB-based sensing assay. This indicated that the material can be used in the glucose sensing assay of a real biological analyte.

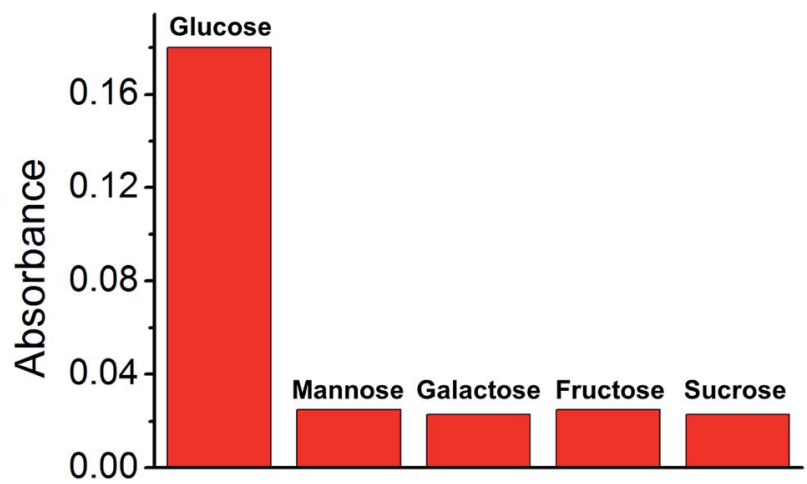

Fig. 9 Selectivity test of Cu@C-500 towards various sugars.

Table 3 Recycling test of Cu@C-500

\begin{tabular}{lllllr}
\hline Number of recycle & 1 & 2 & 3 & 4 & 5 \\
\hline Efficiency (\%) & 100 & 84 & 55 & 25 & 1
\end{tabular}

Due to the stable nature of the composite material, we assumed that the material in the glucose sensing assay could be

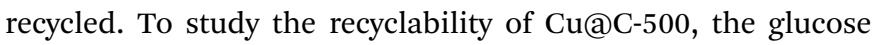
sensing assay was carried out in large scale. The composite material was recovered after glucose sensing assay by centrifugation (12 $000 \mathrm{rpm})$, and reused for a number of cycles. For the recycling experiment, a $300 \mu \mathrm{M}$ glucose solution was used in the GOx-TMB assay. The recycling efficiency was calculated by comparing the UV-Vis absorbance $(652 \mathrm{~nm})$ to that of the first cycle experiment. In the second GOx-TMB assay, the absorbance was decreased to $84 \%$. The absorbance was further decreased as the number of assay cycles increased, so that the material exhibited almost negligible activity in the $5^{\text {th }}$ cycle of the GOx-TMB assay (Table 3). To study the reason for this decrease in catalytic activity, we studied the structural nature of the $\mathrm{Cu}$ nanoparticles by PXRD analysis (Fig. S3†). After the composite was recycled, new PXRD peaks corresponding to $\mathrm{Cu}_{2} \mathrm{O}$ appeared. Therefore, we concluded that the decrease of $\mathrm{Cu}$ nanoparticles and the increase in $\mathrm{Cu}_{2} \mathrm{O}$ nanoparticles, caused by recycling, led to a decrease in the catalytic activity of $\mathrm{Cu} @ \mathrm{C}-500$. In addition, the lowest catalytic activity of $\mathrm{Cu} @ \mathrm{C}-$ 700 can also be explained by the presence of a mixture $\mathrm{Cu}$ and $\mathrm{Cu}_{2} \mathrm{O}$ nanoparticles.

\section{Conclusions}

In this work, we present systematic study for the preparation of a pure copper nanoparticle embedded porous carbon material. Simple pyrolysis of HKUST- 1 at $500{ }^{\circ} \mathrm{C}$, under $\mathrm{N}_{2}$ flow allowed the formation of $\mathrm{Cu} @ \mathrm{C}-500$. Copper nanoparticles with an average size of $30 \mathrm{~nm}$ were well distributed in the carbon bed of the composite material. This material exhibited hierarchical porosity comprising micro-, meso-, and macropores. The presence of pure metal nanoparticle and hierarchical porosity of the 
material allows an application for glucose sensing by GOx-TMB assay. Due to the presence of pure copper nanoparticles and hierarchical porosity, Cu@C-500 displays one of the best sensitivities in colorimetric glucose sensing (detection limit: 3.2 $\left.\times 10^{-9} \mathrm{M}\right)$. In addition, Cu@C-500 exhibits high selectivity in glucose compared to other sugars, including mannose, galactose, fructose, and sucrose. Finally, the recycling experiment suggests that the material can be recycled for up to three times with more than $50 \%$ efficiency. However, the catalytic activity continuously decreases after each cycle because of the formation of $\mathrm{Cu}_{2} \mathrm{O}$ in the composite material. The high sensitivity and selectivity of $\mathrm{Cu} @ \mathrm{C}-500$ can help to improve cost-efficient glucose sensing devices. Notably, simple microfluidic glucose sensing kits can be prepared by utilizing the presented material. Furthermore, we are now investigating generality of this synthetic procedure. Based on this study, new metal nanoparticle embedded porous carbon composite can be widely used.

\section{Acknowledgements}

This research was supported by the Gachon University research fund of 2014 (GCU-2014-0119). This work was also supported by the Radiation Technology R\&D program through the NRF of Korea funded by the Ministry of Science, ICT, and Future Planning (Grant NRF-2015M2A2A6021187). X-ray diffraction experiments at PLS-II, 2D-SMC beamline were supported in part by MEST and POSTECH. We thank Mr E. Kim for his help on SEM analysis.

\section{References}

1 S. L. James, Chem. Soc. Rev., 2003, 32, 276-288.

2 J. R. Long and O. M. Yaghi, Chem. Soc. Rev., 2009, 38, 12131214.

3 H.-C. Zhou, J. R. Long and O. M. Yaghi, Chem. Rev., 2012, 112, 673-674.

4 H.-C. Zhou and S. Kitagawa, Chem. Soc. Rev., 2014, 43, 54155418.

5 M. Eddaoudi, J. Kim, N. Rosi, D. Vodak, J. Wachter, M. O'Keeffe and O. M. Yaghi, Science, 2002, 295, 469-472.

6 A. R. Millward and O. M. Yaghi, J. Am. Chem. Soc., 2005, 127, 17998-17999.

7 K. Sumida, D. L. Rogow, J. A. Mason, T. M. McDonald, E. D. Bloch, Z. R. Herm, T.-H. Bae and J. R. Long, Chem. Rev., 2012, 112, 724-781.

8 J. L. C. Rowsell and O. M. Yaghi, Angew. Chem., Int. Ed., 2006, 44, 4670-4679.

9 J. A. Mason, M. Veenstra and J. R. Long, Chem. Sci., 2014, 5, 32-51.

10 J. A. Mason, J. Oktawiec, M. K. Taylor, M. R. Hudson, J. Rodriguez, J. E. Bachman, M. I. Gonzalez, A. Cervellino, A. Guagliardi, C. M. Brown, P. L. Llewellyn, N. Masciocchi and J. R. Long, Nature, 2015, 357-361.

11 J.-R. Li, R. J. Kuppler and H.-C. Zhou, Chem. Soc. Rev., 2009, 38, 1477-1504.

12 J. Jiang, H. Furukawa, Y.-B. Zhang and O. M. Yaghi, J. Am. Chem. Soc., 2016, 138, 10244-10251.
13 Z. R. Herm, E. D. Bloch and J. R. Long, Chem. Mater., 2014, 26, 338.

14 J. Lee, O. K. Farha, J. Roberts, K. A. Scheidt, S. T. Nguyen and J. T. Hupp, Chem. Soc. Rev., 2009, 38, 1450-1459.

15 M. Yoon, R. Srirambalaji and K. Kim, Chem. Rev., 2012, 112, 1196-1231.

16 T. Zhang and W. Lin, Chem. Soc. Rev., 2014, 43, 5982-5993.

17 J. Liu, L. Chen, H. Cui, J. Zhang, L. Zhang and C.-Y. Su, Chem. Soc. Rev., 2014, 43, 6011-6061.

18 Y. Liu, Y. Zhang, J. Chen and H. Pang, Nanoscale, 2014, 6, 10989-10994.

19 J. An, S. J. Geib and N. L. Rosi, J. Am. Chem. Soc., 2009, 131, 8376-8377.

20 M. Yoon, K. Suh, S. Natarajan and K. Kim, Angew. Chem., Int. Ed., 2013, 52, 2688-2700.

21 S. Horike, D. Umeyama and S. Kitagawa, Acc. Chem. Res., 2013, 46, 2376-2384.

22 P. Ramaswamy, N. E. Wong and G. K. H. Shimizu, Chem. Soc. Rev., 2014, 43, 5913-5932.

23 L. E. Kreno, K. Leong, O. K. Farha, M. Allendorf, R. P. V. Duyne and J. T. Hupp, Chem. Rev., 2012, 112, 1105-1125.

24 Y. Cui, Y. Yue, G. Qian and B. Chen, Chem. Rev., 2012, 112, 1126-1162.

25 W. Zhang, Y. Hu, J. Ge, H.-L. Jiang and S. H. Yu, J. Am. Chem. Soc., 2014, 136, 16978-16981.

26 Y. J. Bae, E. S. Cho, F. Qiu, D. T. Sun, T. E. Williams, J. J. Urban and W. L. Queen, ACS Appl. Mater. Interfaces, 2016, 8, 10098-10103.

27 B. Liu, H. Shioyama, T. Akita and Q. Xu, J. Am. Chem. Soc., 2008, 130, 5390-5391.

28 S. J. Yang, T. Kim, J. H. Im, Y. S. Kim, K. Lee, H. Jung and C. R. Park, Chem. Mater., 2012, 24, 464-470.

29 S. Lim, K. Suh, Y. Kim, M. Yoon, H. Park, D. N. Dybtsev and K. Kim, Chem. Commun., 2012, 48, 7447-7449.

30 S. J. Yang, S. Nam, T. Kim, J. H. Im, H. Jung, J. H. Kang, S. Wi, B. Park and C. R. Park, J. Am. Chem. Soc., 2013, 135, 73947397.

31 K. J. Lee, S. Choi, S. Park and H. R. Moon, Chem. Mater., 2014, 28, 4403-4408.

32 E. Kim and M. Yoon, J. Porous Mater., 2015, 22, 1492-1502. 33 J. Tang, R. R. Salunkhe, J. Liu, N. L. Torad, M. Imura, S. Furukawa and Y. Yamaguchi, J. Am. Chem. Soc., 2015, 137, 1572-1580.

34 Y. Zhang, A. Pan, Y. Wang, W. Wei, Y. Su, J. Hu, G. Cao and S. Liang, ACS Appl. Mater. Interfaces, 2016, 8, 17303-17311.

35 I. A. Khan, A. Badshah, M. A. Nadeem, N. Haider and M. A. Nadeem, Int. J. Hydrogen Energy, 2014, 39, 1960919620.

36 H. Tan, C. Ma, L. Gao, Q. Li, Y. Song, F. Xu, T. Wang and L. Wang, Chem.-Eur. J., 2014, 20, 16377-16383.

37 C. Wei, X. Li, F. Xu, H. Tan, Z. Li, L. Sun and Y. Song, Anal. Methods, 2014, 6, 1550-1557.

38 S. S.-Y. Chui, S. M.-F. Lo, J. P. H. Charmant, A. G. Orpen and I. D. Williams, Science, 1999, 283, 1148-1150.

39 N. Wang, B. Li, F. Qiao, J. Sun, H. Fan and S. Ai, J. Mater. Chem. B, 2015, 3, 7718-7723. 
40 Q. Li, G. Tang, X. Xiong, Y. Cao, L. Chen, F. Xu and H. Tan, Sens. Actuators, B, 2015, 215, 86-92.

41 D. Feng, Z. Y. Gu, J. R. Li, H. L. Jiang, Z. Wei and H.-C. Zhou, Angew. Chem., Int. Ed., 2012, 51, 10307-10310.

42 C. K. Wu, M. Yin, S. O'Brien and J. T. Koberstein, Chem. Mater., 2006, 18, 6054-6058.

43 M. C. Biesinger, L. W. M. Lau, A. R. Gerson and R. St. C. Smart, Appl. Surf. Sci., 2010, 257, 887-898.
44 Y. Wang, Y. Lu, W. Zhan, Z. Xie, Q. Kuang and L. Zheng, J. Mater. Chem. A, 2015, 3, 12796-12803.

45 X.-D. Wang, H.-X. Chen, T.-Y. Zhou, Z.-H. Lin, J.-B. Zeng, Z.-X. Xie, X. Chen, K.-Y. Wong, G.-N. Chen and X.-R. Wang, Biosens. Bioelectron., 2009, 24, 3702-3705.

46 Y. Xia, J. Ye, K. Tan, J. Wang and G. Yang, Anal. Chem., 2013, 85, 6241-6247.

47 Q. Liu, H. Li, Q. Zhao, R. Zhu, Y. Yang, Q. Jia, B. Bian and L. Zhu, Mater. Sci. Eng., C, 2014, 41, 142-151. 